\title{
Death and the dying patient
}

Keywords: professional nurse, laparotomy, chemotherapy, peritoneal fluid, hysterectomy

\section{Opinion}

I like to present a patient I see at the moment. She is a 60 year old professional nurse who has worked for more than 30 years in a teaching hospital, also as ahead of her unit. In 2013 she was diagnosed with breast cancer on a mammogram and a biopsy confirmed the diagnosis. She was not operated but treated by an oncologist who told her that the results of chemotherapy are as good as surgery. The tumour responded well and she was happy with the response. One year later she developed ascites and the doctors diagnosed ovarian cancer with pleural and peritoneal fluid. She got a second course of chemotherapy and had a laparotomy thereafter with a total hysterectomy.

She believed that she was now cured of her cancer. One year later the ascites came back and she got her $3^{\text {rd }}$ course of chemotherapy and improved sufficiently to go back to administrative work in her unit. In April this year her tumour markers started to rise from less than 50 to 400 and later to 1400 . Her ascites came back and she decided that she will not go for chemotherapy again because she felt well except some abdominal discomfort. She decided that she would go for a healthy lifestyle, healthy food and food supplements. After a few weeks she vomited at her work and was put on a drip. The doctor who saw her called me and asked if I could she her. She had a very tense abdomen filled with fluid and I offered to tap her at home. I did that with one of her nursing friends being present and we got 8 litres of turbid yellow brown fluid. She felt much better thereafter and decided to try spironolactone and some furosemide for pretibial oedema prn.

Last week I saw her again and she asked me what I thought about her condition and working. It was clear that she was very tired and had lost a lot of weight. I told her that my impression was that she was getting worse and looked tired and weak. Where does she want to be when her illness progressed? She said that she wanted to stay in her own apartment and she has prepared an extra room. I asked who will
Volume 2 Issue 3 - 2018

\author{
Martin Bac \\ Family physician, Faculty of Health Sciences, University of \\ Pretoria, South Africa
}

Correspondence: Martin Bac, Family physician, Faculty of Health Sciences, University of Pretoria, South Africa, Tel +27795896688,Email martin.bac@up.ac.za

Received: April 17, 2018 | Published: May 15, 2018

care for her and where should she put her bed in case she becomes bedridden. She did not know. She did not want to go to her 87 year old father but preferred to stay at home. Who can take care of you? Your nursing friends, a nurse from Sungardens, can you afford to hire a nurse to come and stay with you? She was not sure and needed to think.

I asked her if she had thought about her death and if was had any thoughts about that. She died immediately and said 'I have not yet thought of that'. We discussed advance directives and possible options for her future care. Did she have any wishes for a funeral or cremation? She said she will think about that because she does not know yet. I then offered to be her family physician and she accepted that because her won GP stayed far and does not do home visits. My challenge in this patient was to start the discussion about her prognosis, her ideas about who would care for her, the place where she wanted to die and any advance directives.

\section{Acknowledgements}

None.

\section{Conflict of interest}

The author declares no conflict of interest. 